\title{
Novel Oxidized Derivatives of Antifungal Pyrrolnitrin from the Bacterium Burkholderia cepacia K87
}

\author{
Md. Zakir Sultan, Kyungseok Park, Sang Yeob Lee, Jung Kon Park, Titto Varughese, \\ Surk-Sik Moon
}

Received: February 19, 2008 / Accepted: July 3, 2008

(C) Japan Antibiotics Research Association

\begin{abstract}
The screening of antifungal active compounds from the fermentation extracts of soil-borne bacterium Burkholderia cepacia K87 afforded pyrrolnitrin (1) and two new pyrrolnitrin analogs, 3-chloro-4-(3-chloro-2nitrophenyl)-5-methoxy-3-pyrrolin-2-one (2) and 4-chloro3-(3-chloro-2-nitrophenyl)-5-methoxy-3-pyrrolin-2-one (3). Pyrrolnitrin showed strong antifungal activity against Rhizoctonia solani but the analogs ( $\mathbf{2}$ and $\mathbf{3}$ ) were found to be marginally active. The isolates, $\mathbf{2}$ and $\mathbf{3}$, are believed to be biodegraded derivatives of pyrrolnitrin.
\end{abstract}

Keywords Burkholderia cepacia K87, metabolite, pyrrolnitrin, 3-chloro-4-(3-chloro-2-nitrophenyl)-5methoxy-3-pyrrolin-2-one, 4-chloro-3-(3-chloro-2nitrophenyl)-5-methoxy-3-pyrrolin-2-one

\section{Introduction}

Certain genera of microorganisms like Pseudomonas, Penicillium, Bacillus, and Streptomyces have been known to produce many famous bioactive compounds with antibacterial, antifungal, and antitumor activities. The antimicrobial agents are used to treat the infectious diseases of human beings as well as to control infectious plant pathogens [1].

Introduction of active microbial populations into the soil around seeds and roots of agricultural plants is becoming of great concern with the aim of enhancing plant productivity because those microorganisms stimulate plant growth, control or inhibit the activity of plant pathogens, and improve soil structure [2]. Also, biological control of soilborne plant diseases using rhizospheric microorganisms has been attracting public interest over the use of long-lasting chemicals in the environment in general. For this purpose, pseudomonads, especially fluorescent Pseudomonas species, are the best known microorganisms with plantgrowth-promoting-rhizobacteria (PGPR) activity as well as antimicrobial activity [3, 4]. A variety of different classes of compounds like $\mathrm{N}$-containing heterocycles, unusual amino acids, peptides, and glycolipids have been isolated from pseudomonads [5 7]. Pseudomonas species belonging to rRNA group II of the genus Pseudomonas have been changed to the new genus Burkholderia [8].

In continuation of our research to identify plant growth promoting and antifungal compounds from the rhizospheric soil bacteria in the roots of plants, we isolated pyrrolnitrin and its oxidized derivatives from Burkholderia cepacia K87. The strain K87 induced systemic resistance in cucumber anthracnose caused by Colletotrichum orbiculare and showed antifungal activity against major fungal pathogens like Rhizoctonia solani, Colletotrichum gloeosporioides, and Sclerotinia sclerotiorum.

The methanolic extract of the solid culture of B. cepacia K87 was purified to isolate antifungal pyrrolnitrin [3-chloro-4-(2-nitro-3-chlorophenyl)pyrrole] and two apparently bio-oxidized structures of pyrrolnitrin. In this paper, we describe the isolation and structure-determination
S.-S. Moon (Corresponding author), Md. Z. Sultan, T. Varughese: Department of Chemistry, Kongju National University, Kongju 314-701, Korea,

E-mail: ssmoon@kongju.ac.kr
K. Park, S. Y. Lee: Plant Pathology Division, National Institute of Agricultural Science and Technology, Suwon 441-707, Korea J. K. Park: Arysta Life Science Korea, Cheongju 380-170, Korea 


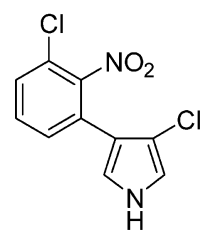

1

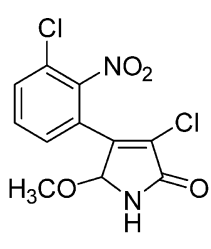

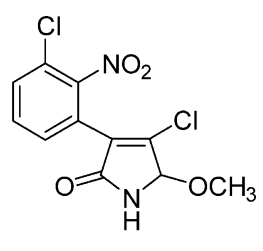

Fig. 1 Chemical structures of the isolated compounds $1 \sim 3$.

of two pyrrolnitrin-like compounds (2 and 3) along with pyrrolnitrin (1) (Fig. 1).

\section{Materials and Methods}

\section{General}

High resolution TOF mass spectra were measured in positive ESI mode on a Waters LCT Premier mass spectrometer (Waters Corporation; Manchester, UK) coupled with a Waters Alliance HPLC system, with data acquisition achieved using MassLynx software, version 4.1. Optical rotations were measured on a Perkin-Elmer 341-LC polarimeter (Perkin-Elmer; Wellesley, MA, USA). UV and IR spectra were measured on a Shimadzu UV-2401 PCR spectrometer (Shimadzu, Kyoto, Japan) and a Perkin-Elmer BX FT-IR spectrometer (Perkin-Elmer Limited, England, UK), respectively. ${ }^{1} \mathrm{H}$ - and ${ }^{13} \mathrm{C}$-NMR spectra were recorded on a Varian Mercury 400 spectrometer (Varian Inc.; Palo Alto, CA, USA), with standard pulse sequences operating at $400 \mathrm{MHz}$ for ${ }^{1} \mathrm{H}-\mathrm{NMR}$ and $100 \mathrm{MHz}$ for ${ }^{13} \mathrm{C}$ spectra. The chemical shifts were given in $\operatorname{ppm}(\delta)$ and were referenced relative to methanol- $d_{4}\left(\delta 3.30\right.$ and $49.15 \mathrm{ppm}$ for ${ }^{1} \mathrm{H}$ - and ${ }^{13} \mathrm{C}-\mathrm{NMR}$, respectively). 2D NMR spectra (COSY, HSQC, HMBC, and NOESY) were recorded using the manufacturer's software VNMR 6.1C. Flash column chromatography was carried out on a column packed with reversed phase C-18 silica gel $(40 \sim 63 \mu \mathrm{m}, 90 \times 100 \mathrm{~mm}$, Merck, Darmstadt, Germany). Medium-pressure liquid chromatography (MPLC) was carried out on a Yamazen instrument (model GR-200, pump 540, Yamazen, Osaka, Japan) using a column packed with reversed phase C-18 silica gel (Cosmosil 40 C-18 Prep, $40 \times 320 \mathrm{~mm}$, Nacalai Tesque Inc, Kyoto, Japan) at a flow rate of $5 \mathrm{ml} /$ minute. TLC was performed on precoated silica gel plates (Kieselgel 60, $\mathrm{F}_{254}, 20 \times 20 \mathrm{~cm}, 0.25 \mathrm{~mm}$ thick, Merck, Darmstadt, Germany). Spots were visualized under UV light at 254 and $365 \mathrm{~nm}$ or by dipping in a methanolic solution of $p$-anisaldehyde - sulfuric acid ( $3: 1)$ followed by heating. Preparative HPLC was performed on a Waters 600 model system (Waters, MA, USA) with a 996 photodiode array UV detector and a reversed phase C-18 column (Chromosep, Microsorb 100-5 C-18, 21.4×250 mm, Varian, CA, USA) at a flow rate of $7 \mathrm{ml} /$ minute at $210 \mathrm{~nm}$. The fungal strain $R$. solani AG-4 (NIAST B-1 strain) was received from the National Institute of Agricultural Science and Technology (Suwon, Korea). Potato dextrose agar (PDA), tryptic soy broth (TSB), and King's B agar (KBA) were purchased from Becton Dickinson and Company (Sparks, MD, USA).

\section{Identification and Culture Conditions of the Bacterial Strain, B. cepacia $\mathrm{K87}$}

The strain K87 was isolated from the rhizosphere of Chinese cabbage and identified as B. cepacia by sequence analysis of $16 S$ rRNA gene using the NCBI BLAST search (http://www.ncbi.nlm.nih.gov/BLAST/). B. cepacia K87 was maintained at $-80^{\circ} \mathrm{C}$ in the TSB media amended with $20 \%$ glycerol. The strains streaked from $-80^{\circ} \mathrm{C}$ were precultured at $28^{\circ} \mathrm{C}$ and inoculated onto Petri dishes containing solidified media (KBA). The dishes were incubated at $28^{\circ} \mathrm{C}$ for 7 days.

\section{Extraction and Isolation}

The solid culture media (10 liters) were harvested and crushed into smaller pieces by using a mechanical stirrer. The media were soaked in $\mathrm{MeOH}$ (20 liters) for 2 days at room temperature. The methanol layer was decanted and the remaining solids were washed with an additional amount of $\mathrm{MeOH}$ (10 liters). The combined methanolic extracts were concentrated to yield a brownish residue $(180 \mathrm{~g})$. The residue was suspended in water $(100 \mathrm{ml})$ and subjected to reversed phase C-18 flash column chromatography with a stepwise gradient elution of a mixture of water and $\mathrm{MeOH}$ to afford eleven fractions (1 liter/each fraction). On the basis of TLC, the eluates from $60 \sim 80 \%$ aq $\mathrm{MeOH}$ (fraction 7, 8, and 9) were combined and evaporated under reduced pressure to yield a brown oily residue $(578.7 \mathrm{mg})$. The residue was further chromatographed on a reversed phase C-18 column (MPLC) with a gradient elution of $50 \%$ aq $\mathrm{MeOH}$ to $100 \%$ $\mathrm{MeOH}$ for 180 minutes to afford four subfractions. The active subfractions 3 and 4 were combined $(279.4 \mathrm{mg})$ and purified by reversed phase HPLC (30 60\% aq MeCN for 70 minutes) to afford compounds, $2(6.0 \mathrm{mg}, \mathrm{Rt}=35.1$ minutes), 3 (3.2 mg, $\mathrm{Rt}=37.7$ minutes), and $\mathbf{1}$ (14.4 mg, $\mathrm{Rt}=68.9$ minutes).

3-Chloro-4-(3-chloro-2-nitrophenyl)-5-methoxy-3-pyrrolin2-one (2)

Light brown oil; $[\alpha]_{\mathrm{D}}^{20}-2.4(c 0.25, \mathrm{MeOH}) ; \mathrm{UV}(\mathrm{MeCN})$ 
$\lambda_{\text {max }}(\log \varepsilon) \mathrm{nm} 214$ (4.15), 303 (3.21); IR (KBr) $v_{\max } \mathrm{cm}^{-1}$ 3448, 2926, 1718, 1654, 1541, 1508, 1458, 1061; ${ }^{1} \mathrm{H}-\mathrm{NMR}$ $\left(400 \mathrm{MHz}, \mathrm{CD}_{3} \mathrm{OD}\right) \delta 7.80\left(1 \mathrm{H}, \mathrm{d}, J=8.0 \mathrm{~Hz}, \mathrm{H}-4^{\prime}\right), 7.69$ $\left(1 \mathrm{H}, \mathrm{t}, J=8.0 \mathrm{~Hz}, \mathrm{H}-5^{\prime}\right), 7.57\left(1 \mathrm{H}, \mathrm{d}, J=8.0 \mathrm{~Hz}, \mathrm{H}-6^{\prime}\right), 5.49$ $(1 \mathrm{H}, \mathrm{s}, \mathrm{H}-5), 3.31\left(3 \mathrm{H}, \mathrm{s}, \mathrm{OCH}_{3}\right) ;{ }^{13} \mathrm{C}-\mathrm{NMR}(100 \mathrm{MHz}$, $\left.\mathrm{CD}_{3} \mathrm{OD}\right) \delta 167.0$ (C, C-2), $149.4\left(\mathrm{C}, \mathrm{C}-2^{\prime}\right), 145.6$ (C, C-4), $133.3\left(\mathrm{CH}, \mathrm{C}-4^{\prime}\right), 133.2\left(\mathrm{CH}, \mathrm{C}-5^{\prime}\right), 132.2$ (C, C-3), 130.7 $\left(\mathrm{CH}, \mathrm{C}-6^{\prime}\right), 127.0^{a}\left(\mathrm{C}, \mathrm{C}-1^{\prime}\right), 126.9^{a}\left(\mathrm{C}, \mathrm{C}-3^{\prime}\right), 87.2(\mathrm{CH}$, $\mathrm{C}-5), 55.6\left(\mathrm{CH}_{3}, \mathrm{OCH}_{3}\right)\left({ }^{a}\right.$ values are interchangeable); HRTOFMS (+ESI mode) $[\mathrm{M}+\mathrm{H}]^{+} \mathrm{m} / z 302.9931$ (calcd. for $\left.\mathrm{C}_{11} \mathrm{H}_{9} \mathrm{Cl}_{2} \mathrm{~N}_{2} \mathrm{O}_{4}+\mathrm{H}, 302.9939\right)$; $\mathrm{Rf}$ (3: 7 hexane - EtOAc) 0.23 .

4-Chloro-3-(3-chloro-2-nitrophenyl)-5-methoxy-3-pyrrolin2-one (3)

Light brown oil; $[\alpha]_{\mathrm{D}}^{20}+11.90$ (c 0.063, MeOH); UV $(\mathrm{MeCN}) \lambda_{\max }(\log \varepsilon) \mathrm{nm} 214$ (3.98), 306 (3.06); IR (Nujol) $\mathrm{cm}^{-1} 3423,2932,1719,1541,1363,1204,1132 ;{ }^{1} \mathrm{H}-\mathrm{NMR}$ $\left(400 \mathrm{MHz}, \mathrm{CD}_{3} \mathrm{OD}\right) \delta 7.78\left(1 \mathrm{H}, \mathrm{dd}, J=8.0,1.2 \mathrm{~Hz}, \mathrm{H}-4^{\prime}\right)$, $7.70\left(1 \mathrm{H}, \mathrm{t}, J=8.0 \mathrm{~Hz}, \mathrm{H}-5^{\prime}\right), 7.52(1 \mathrm{H}, \mathrm{dd}, J=8.0,1.2 \mathrm{~Hz}$, H-6' $), 58(1 \mathrm{H}, \mathrm{s}, \mathrm{H}-5), 3.31\left(3 \mathrm{H}, \mathrm{s}, \mathrm{OCH}_{3}\right) ;{ }^{13} \mathrm{C}-\mathrm{NMR}$ $\left(100 \mathrm{MHz}, \mathrm{CD}_{3} \mathrm{OD}\right) \delta 169.4(\mathrm{C}, \mathrm{C}-2), 149.2\left(\mathrm{C}, \mathrm{C}-2^{\prime}\right)$, $148.1(\mathrm{C}, \mathrm{C}-4), 133.5^{a}(\mathrm{C}, \mathrm{C}-3), 133.5^{a}\left(\mathrm{CH}, \mathrm{C}-4^{\prime}\right), 133.5^{a}$ $\left(\mathrm{CH}, \mathrm{C}-5^{\prime}\right), 131.6\left(\mathrm{CH}, \mathrm{C}-6^{\prime}\right), 127.7^{b}\left(\mathrm{C}, \mathrm{C}-1^{\prime}\right), 126.3^{b}(\mathrm{C}$, $\left.\mathrm{C}-3^{\prime}\right), 87.3(\mathrm{CH}, \mathrm{C}-5), 51.8\left(\mathrm{CH}_{3}, \mathrm{OCH}_{3}\right)\left({ }^{a}\right.$ values are overlapped, ${ }^{b}$ values are interchangeable); HRTOFMS $\left(+\mathrm{ESI}\right.$ mode) $[\mathrm{M}+\mathrm{H}]^{+} \mathrm{m} / \mathrm{z} \quad 302.9929 \quad$ (calcd. for $\left.\mathrm{C}_{11} \mathrm{H}_{9} \mathrm{Cl}_{2} \mathrm{~N}_{2} \mathrm{O}_{4}+\mathrm{H}, 302.9939\right)$. Rf (3: 7 hexane-EtOAc) 0.26 .

\section{Antifungal Assay}

The antifungal activity against $R$. solani was determined by paper disc diffusion assay. In brief, a small mycelial plug cut from the actively growing front of a week-old colony of $R$. solani was placed on the center of the Petri dish with sterilized autoclaved agar media (PDA $3.9 \mathrm{~g}$ in $100 \mathrm{ml}$ water). After incubation of the dishes at $28^{\circ} \mathrm{C}$ for a day the filter paper discs ( $8 \mathrm{~mm}$ in diameter) impregnated with specified concentrations of samples were placed near the mycelium. The zone of fungal growth inhibition was measured in diameter after 3-day incubation at $28^{\circ} \mathrm{C}$.

\section{Results and Discussion}

The bacterial strain B. cepacia $\mathrm{K} 87$ was fermented in KBA media at $28^{\circ} \mathrm{C}$ for 7 days. The solid culture media (10 liters) were soaked with $\mathrm{MeOH}$. The resulting crude extract was concentrated and subjected to a series of chromatographic purification procedures like reversed phase C-18 medium pressure and C-18 HPLC.
Compounds, 1, 2, and 3 were obtained in yield of 14.4, 6.0, and $3.2 \mathrm{mg}$, respectively, from the crude extract (180 g).

Compound 1 was isolated as a light brown oil and established as pyrrolnitrin by comparison of the spectroscopic data with those reported in the literature [9 11]. Compound 2 was obtained as a light brown oil with a specific rotation of $-2.4(c 0.25, \mathrm{MeOH})$. The mass spectrum (HRTOFMS) displayed a protonated molecular ion $[\mathrm{M}+\mathrm{H}]^{+}$at $\mathrm{m} / \mathrm{z} 302.9931$ (calcd. for $[\mathrm{M}+\mathrm{H}]$, 302.9939), indicating of a molecular formula of $\mathrm{C}_{11} \mathrm{H}_{9} \mathrm{Cl}_{2} \mathrm{~N}_{2} \mathrm{O}_{4}$. The UV maxima were observed at 214 and $303 \mathrm{~nm}$. The IR spectrum showed the characteristic peaks at 3448,1718 , and $1654 \mathrm{~cm}^{-1}$, suggesting of the presence of $\mathrm{OH}$ ( or $\mathrm{NH}$ ), $\mathrm{C}=\mathrm{O}$, and $\mathrm{C}=\mathrm{C}$ bonds. The ${ }^{1} \mathrm{H}-\mathrm{NMR}$ spectrum of compound 2 showed proton signals $[\delta 7.69(\mathrm{t}$, $J=8.0 \mathrm{~Hz}), 7.80(\mathrm{~d}, J=8.0 \mathrm{~Hz})$, and $7.57(\mathrm{~d}, J=8.0 \mathrm{~Hz})]$ for a characteristic $\mathrm{ABC}$ spin pattern of a trisubstituted benzene ring, a singlet proton signal $(\delta 3.31)$ for a methoxy group, and a singlet proton signal $(\delta 5.49)$ for a methine group. In the ${ }^{1} \mathrm{H}-{ }^{1} \mathrm{H}$ COSY spectrum, the aromatic proton at $\delta 7.69\left(\mathrm{H}-5^{\prime}\right)$ was coupled with the protons at $\delta 7.80(\mathrm{H}-$ $\left.4^{\prime}\right)$ and 7.57 (H-6'). Their corresponding carbon signals were assigned from the HSQC spectrum as $\delta 133.2\left(\mathrm{C}-5^{\prime}\right)$, $133.3\left(\mathrm{C}-4^{\prime}\right), 130.7$ (C-6'), respectively. In the HBMC spectrum, the protons $\left(\mathrm{H}-4^{\prime}\right.$ and $\left.\mathrm{H}-6^{\prime}\right)$ showed correlations with the quaternary carbon signal at $\delta 149.4\left(\mathrm{C}-2^{\prime}\right)$; the proton $\left(\mathrm{H}-5^{\prime}\right)$ with two quaternary aromatic signals at $\delta$ $126.9\left(\mathrm{C}-3^{\prime}\right)$ and $127.0\left(\mathrm{C}-1^{\prime}\right)$. From these NMR data analysis the trisubstituted benzene moiety could be deducible to be 3-chloro-2-nitrophenyl group as the same moiety as that in compound $\mathbf{1}$, as the benzene proton signals in compound $\mathbf{2}$ are relatively well resolved unlike those in compound $\mathbf{1}$ in which they appeared overlapped. In addition, the $\mathrm{HMBC}$ spectrum revealed that the singlet proton at $\delta 5.49$ (H-5) attached to the carbon $\mathrm{C}-5$ ( $\delta$ 87.2) showed long range correlations with the remaining three quaternary carbons at $\delta 167.0(\mathrm{C}-2), 145.6$ (C-4), and $132.2(\mathrm{C}-3)$, and the methoxy carbon at $\delta 55.6$. This moiety could be assignable to a $\mathrm{HC}(\mathrm{OMe})-\mathrm{C}=\mathrm{C}-\mathrm{C}=\mathrm{O}$ group with a long range connection of the methine carbon to the $\mathrm{C}=\mathrm{O}$ group, thus, from the molecular formula, a 4-substituted 5methoxy-3-chloro-pyrrolin-2-onyl group. The quaternary carbon at 145.6 (C-4) in this pyrrolinone moiety showed an important correlation with the proton $\left(\mathrm{H}-6^{\prime}\right)$ in the 3chloro-2-nitrophenyl group. This information establishes the direct connectivity between the two moieties (Fig. 2). In addition, a weak NOE was observed between the aromatic proton (H-6') and the methoxy protons (H-6), confirming that those groups are in vicinity in their spatial arrangement. From the above spectral analyses, the structure of compound 2 was determined to be 3 -chloro-4- 


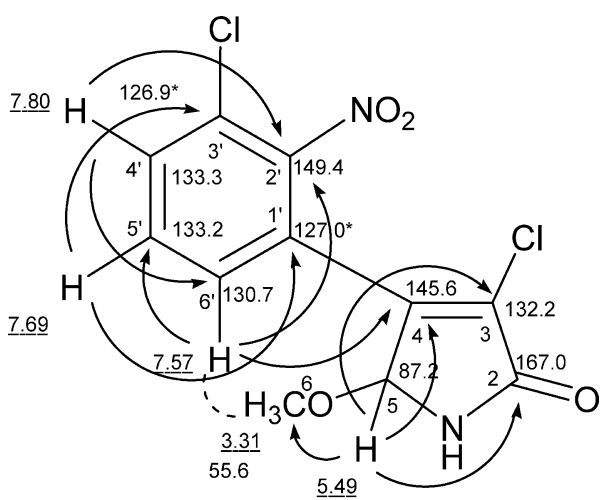

2

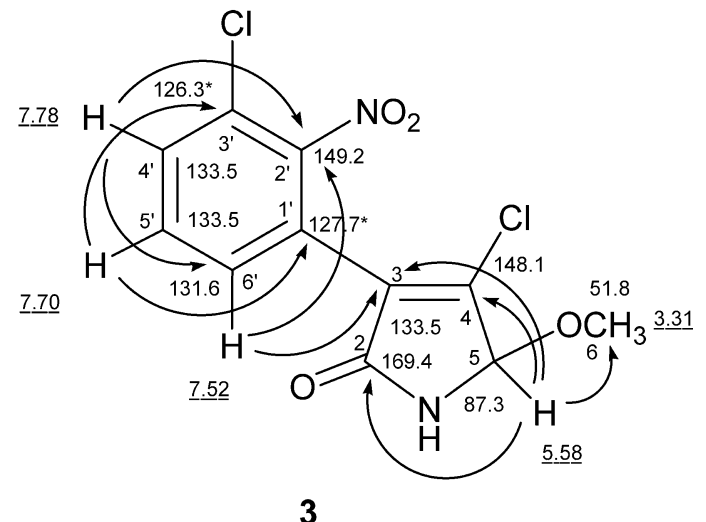

3

Fig. $2{ }^{1} \mathrm{H}$ - (underline) and ${ }^{13} \mathrm{C}-\mathrm{NMR}$ assignments (values with asterisks interchangeable with each other within the structure), and HMBC (solid arrows; H to C) and NOE (dashed curve) correlations in compounds 2 and $\mathbf{3}$.

(3-chloro-2-nitrophenyl)-5-methoxy-3-pyrrolin-2-one.

Compound 3 was obtained as a light brown oil $\left([\alpha]_{\mathrm{D}}^{20}\right.$ $+11.9, c 0.063$, MeOH). The UV spectrum was similar with that of compound 2. In the IR spectrum, the $\mathrm{OH}$ (or $\mathrm{NH}), \mathrm{C}=\mathrm{O}$, and $\mathrm{C}=\mathrm{C}$ bonds were also indicated. The mass spectrum (HRTOFMS) of compound $\mathbf{3}$ indicated its molecular formula as the same as that of compound $\mathbf{2}$. The ${ }^{1} \mathrm{H}$ - and ${ }^{13} \mathrm{C}-\mathrm{NMR}$ data of the aromatic region of compound $\mathbf{3}$ was quite similar with those of compound $\mathbf{2}$, indicating of the presence of 3-chloro-2-nitrophenyl group. In the $\mathrm{HMBC}$, the proton (H-5) at $\delta 5.58$ showed long range correlations with three quaternary carbons at $\delta 169.4$ (C-2), 148.1 (C-4), and 133.5 (C-3), and methoxy carbon (C-6) at $\delta 51.8$, which indicates again the presence of pyrrolinone group (Fig. 2). Unlike compound 2, no NOE was observed between the proton (H-6') and methoxy protons (H-6) at $\delta$ 3.31. From these data we suggest the structure of compound 3 could be determined to be 4-chloro-3(3-chloro-2-nitrophenyl)-5-methoxy-3-pyrrolin-2-one, a regioisomer of compound 2 . It should be noted that the long range correlation of the proton $\left(\mathrm{H}-6^{\prime}\right)$ at $\delta 7.52$ with the quaternary carbon $(\mathrm{C}-3)$ in the $\mathrm{HMBC}$ was not unambiguous because the $\mathrm{C}-3$ carbon appeared overlapped with the other two carbons $\left(\mathrm{C}-4^{\prime}\right.$ and $\left.\mathrm{C}-5^{\prime}\right)$. It is reasonable to accept that the $\alpha, \beta$-unsaturated $\mathrm{C}=\mathrm{O}$ groups in the pyrrole moiety of compounds $\mathbf{2}$ and $\mathbf{3}$ seem influenced the chemical shifts of the $\beta$-carbons at $\delta 145.6(\mathrm{C}-3)$ in compound 2 and $\delta 148.1$ (C-4) in compound 3 to shift down-field. However, in compound 2, there was no significant red shift in the UV nor down field chemical shifts of the aromatic carbons $\left(\mathrm{C}-2^{\prime}, \mathrm{C}-4^{\prime}\right.$, and $\left.\mathrm{C}-6^{\prime}\right)$ due to the carbonyl group, which suggests that the benzene and pyrrolinone rings are not fairly in the same plane, as indicated in the case of pyrrolinitrin $\mathbf{1}$ [12]. The absolute configuration at C-5 in compounds 2 and $\mathbf{3}$ was not determined.

The isolated pyrrolnitrin (1) exhibited strong antifungal activity against $R$. solani at a concentration of $50 \mu \mathrm{g} / \mathrm{disc}$ ( $25 \mathrm{~mm}$ of inhibition zone in diameter) by paper disc diffusion assay, but compounds, $\mathbf{2}$ and $\mathbf{3}$, showed a relatively low activity even at $250 \mu \mathrm{g} / \mathrm{disc}(10 \mathrm{~mm}$ of inhibition zone). For the antifungal assay, ketoconazole was used as a positive control, which showed $11 \mathrm{~mm}$ of inhibition zone at $30 \mu \mathrm{g} / \mathrm{disc}$. It has been reported that pyrrolnitrin (1) was isolated from many pseudomonads like Pseudomonas, Burkholderia, and Serratia species showing antifungal activity [10, 11, 13 15].

Although compound $\mathbf{1}$ had been shown to be strongly active against fungi, yeasts, and Gram-positive bacteria, it was not sufficiently stable upon exposure to sunlight resulting in a loss of its antibiotic activity for agricultural purpose [9]. It was also reported that the pyrrole ring of compound $\mathbf{1}$ was readily metabolized in vivo in rat and in vitro by enzymes like mixed-function oxidases to succinimide, pyrrolinone, and maleimide derivatives, resulting in no pyrrolnitrin-like antifungal activity [16]. Much of the work in structural modification of this compound has been focused on an increase of its photostability. Pyrrolnitrin derivatives such as 3-cyano-4aryl pyrroles have been developed to improve photostability for agricultural purpose [17]. Recently, the UV irradiation to compound 1 was reported to produce 7,4'-dichlorospiro[1,3-dihydrobenzeno(c)isoxazole-3,3' -pyrrolin-2' one] in an aprotic solvent via intramolecular oxidation of the pyrrole ring by the triplet-excited nitro group and 3,7-dichloro-8-hydroxy-8,8a-dihydropyrrolo[2,3-b]indol2 -one in an aqueous solvent via intramolecular cyclization by the singlet-excited nitro group followed by hydroxylation. 


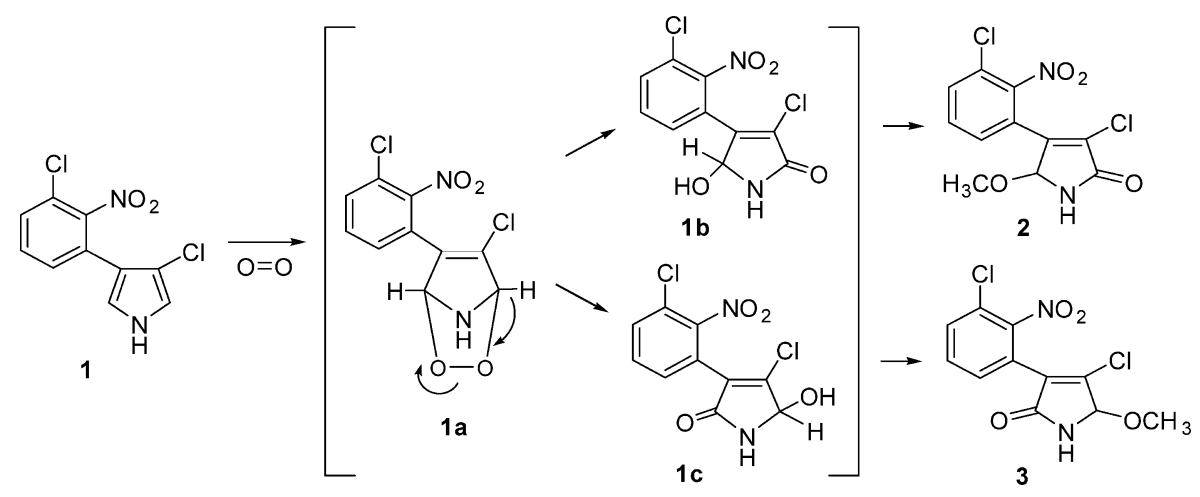

Scheme $\mathbf{1}$ Postulated pathways to compounds $\mathbf{2}$ and $\mathbf{3}$ from compound $\mathbf{1}$ (electron movements in compound $\mathbf{1 a}$ to compound $\mathbf{2}$ for heterolytic cleavage are shown).

These photoproducts were reported to show no remarkable antifungal activities [18]. The two new isolates, $\mathbf{2}$ and $\mathbf{3}$, could be biosynthetically generated from compound 1 by oxidation during fermentation via a [4+2] cycloaddition (dioxine 1a) of the diene group of the pyrrole ring with oxygen followed by rearrangement (pyrrolinones $\mathbf{1 b}$ and 1c) and ketalization with $\mathrm{MeOH}$ (or methylation of the hemiketal $\mathrm{OH}$ group), as shown in Scheme 1. The suggested pyrrolinone intermediate 1c has been isolated previously as a metabolite from compound $\mathbf{1}$ in vitro using rat liver microsomes supplemented with NADPH [16]. As an analogy in the mechanism shown in the Scheme 1, it was reported that 1,2-dioxines was readily prepared chemically from dienes with oxygen by photooxidation using a photosensitizer under UV light. The dioxines are readily ring-opened homolytically via use of transition metal catalysts like $\mathrm{Co}(\mathrm{II})$ and $\mathrm{Ru}(\mathrm{II})$ or heterolytically under basic condition to yield $\gamma$-hydroxy enones [19 21].

In conclusion, pyrrolnitrin-like compounds, $\mathbf{2}$ and $\mathbf{3}$, were isolated from the fermentation broth of $B$. cepacia K87. They would be biosynthetic intermediates for degradation of compound $\mathbf{1}$ via oxidation during fermentation causing of a loss of antifungal activity. The proposed degradation pathway would suggest the inactivation route of antibiotic 1.

Acknowledgement This work was supported by grants from the Agricultural R \& D Promotion Center, Korea (Grant No.50502803-3-HD110).

Supporting Information Available IR, UV, ${ }^{1} \mathrm{H},{ }^{13} \mathrm{C}, \mathrm{COSY}$, HSQC, and HMBC NMR spectra, HPLC profile, and MS spectra for compounds $\mathbf{1} \sim \mathbf{3}$ (only MS and ${ }^{1} \mathrm{H}-\mathrm{NMR}$ for compound $\mathbf{1}$ ).

\section{References}

1. Ōmura S. The search for bioactive compounds from microorganisms; Springer-Verlag, New York, pp. 1-107 and 213-223 (1992)

2. van Veen JA, van Overbeek LS, van Elsas JD. Fate and activity of microorganisms introduced into soil. Microbiol Mol Biol Rev 61: 121-135 (1997)

3. Whipps JM. Microbial interactions and biocontrol in the rhizosphere. J Exp Bot 52: 487-511 (2001)

4. Thomashow LS. Biological control of plant root pathogens. Curr Opin Biotechnol 7: 343-347 (1996)

5. Leisinger T, Margraff R. Secondary metabolites of the fluorescent pseudomonads. Microbiol Rev 43: 422-442 (1979)

6. Moon SS, Kang PM, Park KS, Kim CH. Plant growth promoting and fungicidal 4-quinolinones from Pseudomonas cepacia. Phytochemistry 42: 365-368 (1996)

7. Moon SS, Kang PM, Kim BS, Hwang BK. Spectral evidence of 1,2-linkage in antifungal rhamnolipid produced by Pseudomonas aeruginosa. Bull Korean Chem Soc 17: 291-293 (1996)

8. Coenye T, Vandamme P, Govan JRW, Lipuma JJ. Taxonomy and identification of the Burkholderia cepacia complex. J Clin Microbiol 39: 3427-3436 (2001)

9. Arima K, Imanaka H, Kousaka M, Fukuda A, Tamura G. Studies on pyrrolnitrin, a new antibiotic. I. Isolation and properties of pyrrolnitrin. J Antibiot 18: 201-204 (1965)

10. Burkhead KD, Schisler DA, Slininger PJ. Pyrrolnitrin production by biological control agent Pseudomonas cepacia b37w in culture and in colonized wounds of potatoes. Appl Environ Microbiol 60: 2031-2039 (1994)

11. El-Banna N, Winkelmann G. Pyrrolnitrin from Burkholderia cepacia: antibiotic activity against fungi and novel activities against streptomycetes. J Appl Microbiol 85: 69-78 (1998)

12. Morimoto Y, Hashimoto M, Hattori K. The crystal structure of pyrrolnitrin. Tetrahedron Lett 9: 209-211 (1968) 
13. Cain CC, Lee D, Waldo III RH, Henry AT, Casida EJ Jr, Wani MC, Wall ME, Oberlies NH, Falkinham III JO. Synergistic antimicrobial activity of metabolites produced by a nonobligate bacterial predator. Antimicrob Agents Chemother 47: 2113-2117 (2003)

14. Levenfors JJ, Hedman R, Thaning C, Gerhardson B, Welch CJ. Broad-spectrum antifungal metabolites produced by the soil bacterium Serratia plymuthica A 153. Soil Biol Biochem 36: 677-685 (2004)

15. Hwang J, Chilton WS, Benson DM. Pyrrolnitrin production by Burkholderia cepacia and biocontrol of rhizoctonia stem rot of poinsettia. Biol Control 25: 56-63 (2002)

16. Murphy PJ, Williams TL. Biological inactivation of pyrrolnitrin. Identification and synthesis of pyrrolnitrin metabolites. J Med Chem 15: 137-139 (1972)

17. Godfrey CRA. Agrochemicals from natural products;
Marcel Dekker, Inc., New York, pp. 322-324 (1994)

18. Sako M, Kihara T, Tanisaki M, Maki Y, Miyamae A, Azuma T, Kohda S, Masugi T. Novel photodegradation of the antifungal antibiotic pyrrolnitrin in anhydrous and aqueous aprotic solvents. J Org Chem 67: 668-673 (2002)

19. Greatrex BW, Kimber MC, Taylor DK, Fallon G, Tiekink ERT. 1,2-dioxines as masked cis $\gamma$-hydroxy enones and their versatility in the synthesis of highly substituted $\gamma$-lactones. J Org Chem 67: 5307-5314 (2002)

20. Herz W, Juo RR. Photooxygenation of 1-vinylcycloalkenes. The competition between "ene" reaction and cycloaddition of singlet oxygen. J Org Chem 50: 618-627 (1985)

21. Sengul ME, Simsek N, Balci M. An unprecedented Co ${ }^{\text {II }}$ tetraphenylporphyrin-catalyzed decomposition of bicyclic endoperoxides: a new approach to substituted furofuran systems. Eur J Org Chem 2000: 1359-1363 (2000) 